\title{
Impact of Surface Tension in Pharmaceutical Sciences
}

\author{
Anahita Fathi-Azarbayjani ${ }^{\mathrm{a}}$, Abolghasem Jouyban ${ }^{\mathrm{b}}$, Sui Yung Chan ${ }^{\mathrm{a}}$ \\ ${ }^{a}$ Department of Pharmacy, National University of Singapore, Singapore \\ ${ }^{b}$ Faculty of Pharmacy and Drug Applied Research Center, Tabriz University (Medical Sciences), Tabriz, Iran
}

Received, December 12, 2008; Revised, July 1, 2009; Accepted July 14, 2009; Published, August 12, 2009

\begin{abstract}
Surface chemistry has a large influence in many industries. In the life sciences, surface area is gaining importance in the characterization of materials during their development, formulation and manufacturing. The chemical activity, adsorption, dissolution, and bioavailability of a drug may depend on the surface of the molecule. In order to meet manufacturing challenges and develop new and better performing products with improved qualities, knowledge of surface tension is of utmost importance. An attempt has been made in this paper to review the application of interfacial tension in the key domains of pharmaceutical applications.
\end{abstract}

\section{INTRODUCTION}

The role of interfaces in our daily life becomes increasingly apparent. The advancement achieved in surface chemistry has led to countless applications in a multitude of industries, for example, interfaces are crucially important in pharmaceutics, biotechnology and biomedicine. Due to this increased interest, there is a growing need for specific interfacial consideration that can be used routinely to solve pharmaceutical problems and improve product quality.

In order to meet challenges and develop new and better performing products, knowledge of surface tension is of utmost importance. Surface chemistry deals with chemical processes at the interface between two phases, therefore surface properties and their manipulation in a certain application area play important roles. This article addresses the applications of surface tension in pharmaceutical industry, namely pharmaceutical products and dosage forms.

\section{Dosage Forms}

\subsection{Solid Dosage Forms}

Tablets are the most popular and widely used dosage forms because of the advantages they offer both to the manufacturer and the patient. These are due, in part, to the ease of administration and handling, and amenability for mass production on a commercial scale at low manufacturing cost. Quality assurance can only be guaranteed through an understanding of varied disciplines and formulation techniques. The mix of powders from which a tablet is made includes an active ingredient and several excipients. Excipients are added to improve compression parameter of the tablet and bioavailability. Binding agents enhance the compaction characteristics of the tablet. It appears that a crucial step in optimizing granulation performance is the wetting of the substrate with the binder, and spreading of the binder over the substrate. Granule morphology can be controlled by the work of adhesion between the two components, $\mathrm{W}_{\mathrm{a}}$ which can be defined from the following equation:

$$
W_{a}=4\left[\frac{\gamma_{1}^{d} \gamma_{2}^{d}}{\gamma_{1}^{d}+\gamma_{2}^{d}}+\frac{\gamma_{1}^{p} \gamma_{2}^{p}}{\gamma_{1}^{d} \gamma_{2}^{p}}\right]
$$

Where $\gamma_{1}$ and $\gamma_{2}$ are the surface free energies of the binder and the substrate respectively, $\gamma^{\mathrm{d}}$ and $\gamma^{\mathrm{p}}$ denote the non-polar and polar contributions of the surface free energy (1). Polymers can be used as binders in tablet formulation. Various polymers behave differently during wetting of tablets. These differences may be explained through material properties such as rheological behavior during wetting process, which changes the final product behavior (2). Starch is one of the most widely used binders in tablet and capsule formulations. Surface tension of starch varies in different species of the plant and thus influences the spreading behavior of

Correspondence Author: Sui Yung Chan, Department of Pharmacy, National University of Singapore, Block S4, level 2, Science Drive 4, 117543, Singapore, phacsy@nus.edu.sg 
Table 1. Contact angle of liquids on parafilm disk and surface energy values using Wu's method

\begin{tabular}{lccl}
\hline Liquid & $\theta\left({ }^{\circ}\right)$ & $\operatorname{Cos} \theta$ & $\gamma$ \\
\hline Water & 65.2 & 0.4195 & 72.0 \\
Glycerol & 66.0 & 0.4067 & 63.7 \\
Formamide & 22.4 & 0.9245 & 58.3 \\
1.3- Propanediol & 31.3 & 0.8545 & 49.2 \\
Ethylene glycol & 28.4 & 0.8796 & 48.9 \\
1,3-Butanediol & 24.3 & 0.9114 & 39.1 \\
1,2-Propanediol & 33.1 & 0.8377 & 38.0 \\
\hline *Data taken from ref (4). & & \\
\hline
\end{tabular}

the binder over the substrate particle. It is thought that the surface tension of a polymer is related to its molecular weight. High interfacial tension will result in formation of thick and hard layers of the binding film with poor moisture penetrability (3).

Surface tension values of some of the vehicles used in pharmaceutical industry are listed in Table 1.

Coating of particles has many applications in pharmaceutical industry, for example tablet coating. Coating can improve product appearance, mask taste and odor or control the rate of drug release. If the surface tension is too high, the wetting process will be hindered. In addition, if the surface tension is too low the leveling process will be influenced leading to an orange peel surface. Therefore, it is important to control the surface tension of the coating solution for a presentable product. Surface tension of powder coating can be adjusted by addition of surface flow additives such as surfaceactive agents (5).

One of the many methods of tablet coating is film coating. Film coating is defined as the adhesion and spreading of polymers over the tablet surface, therefore the surface tension of the polymer solution will have a major influence on these interfacial events. Characteristics of the coating suspension such as rheological behavior and contact angle between the suspension drop and the particle surface influences the film formation process (4). Surface active molecules adsorb at the liquid air interface and lower the surface tension of the solution and are widely used in formulation science $(4,6)$. Table 2 lists surface tension values of some of the surfactants used in the pharmaceutical industry.

Table 2. Surface tension and CMC value of surfactants at $25^{\circ} \mathrm{C}$.

\begin{tabular}{|c|c|c|c|}
\hline Surfactant & Mol. weight & $\begin{array}{l}\text { Surfactant Concentration } \\
\qquad(\mathrm{g} / \mathrm{ml})\end{array}$ & $\begin{array}{l}\text { Surface tension } \\
\qquad(\mathrm{mN} / \mathrm{m})\end{array}$ \\
\hline AOT (Dioctyl sulfosuccinate) & 444.5 & $\begin{array}{l}2.5 \times 10^{-4} \\
1.0 \times 10^{-2}\end{array}$ & $\begin{array}{l}41.3 \\
26.1\end{array}$ \\
\hline HTAB (Hexadecyltrimethyl ammonium bromide) & 364.5 & $\begin{array}{l}2.5 \times 10^{-4} \\
1.0 \times 10^{-2}\end{array}$ & $\begin{array}{l}41.5 \\
35.4\end{array}$ \\
\hline $\begin{array}{l}\text { Tween } 20 \text { (Polyoxyethylene } 20 \text { sorbitan mono- } \\
\text { laurate) }\end{array}$ & 1126 & $\begin{array}{l}3.0 \times 10^{-5} \\
1.0 \times 10^{-2}\end{array}$ & $\begin{array}{l}36.3 \\
33.5\end{array}$ \\
\hline Brij 35 (Polyoxyethylene 23 lauryl ether) & 1200 & $\begin{array}{l}2.0 \times 10^{-4} \\
1.0 \times 10^{-2}\end{array}$ & $\begin{array}{l}42.1 \\
42.8\end{array}$ \\
\hline SLS (Sodium lauryl sulfate) & 288.3 & $\begin{array}{l}5.8 \times 10^{-3} \\
2.0 \times 10^{-2}\end{array}$ & $\begin{array}{l}39.4 \\
37.9\end{array}$ \\
\hline $\begin{array}{l}\text { Tween } 80 \text { (Polyoxyethylene } 20 \text { sorbitan mono- } \\
\text { oleate) }\end{array}$ & 1309 & $\begin{array}{l}2.5 \times 10^{-4} \\
2.0 \times 10^{-2}\end{array}$ & $\begin{array}{l}38.3 \\
33.9\end{array}$ \\
\hline $\begin{array}{l}\text { TXR / Triton X-100 (Polyoxyethylene } 9 \text { p-isooctyl } \\
\text { phenyl ether) }\end{array}$ & 624.9 & $\begin{array}{l}4.0 \times 10^{-5} \\
5.0 \times 10^{-3}\end{array}$ & $\begin{array}{l}39.6 \\
29.3\end{array}$ \\
\hline DCH (Sodium deoxycholate) & 414.6 & $2.0 \times 10^{-2}$ & 45.0 \\
\hline POE 10 LE (Polyoxyethylene 10 lauryl ether) & 672 & $\begin{array}{l}4.0 \times 10^{-6} \\
1.0 \times 10^{-2}\end{array}$ & $\begin{array}{l}39.3 \\
30.9\end{array}$ \\
\hline Water & 18 & - & 72.0 \\
\hline
\end{tabular}




\subsubsection{Dissolution and Disintegration}

The rate and extent of drug absorption in the gastrointestinal (GI) tract are determined by factors such as dissolution, disintegration and the aqueous solubility of the drug. These factors should be considered because they have a significant impact on properties of drugs, such as uptake, distribution, transport, and eventually bioavailability $(7,8)$. By applying special surface treatments such as contact angle and surface tension measurements to pharmaceutical compounds, drug distribution, dissolution behavior and release pattern in various body fluids can be improved. In vitro conditions designed to simulate the physiological environments of the GI tract should be controlled for drug dissolution experiments which mimic the in vivo conditions (9). The surface tension of human gastric juice is in the range of $35-45 \mathrm{mNm}^{-1}$ (8). In vitro conditions can be mimicked by the addition of pepsin and/or surfactants to the $\mathrm{HCl}$ solution. Bile salt and phospholipid concentration found in the gastric fluid of fasted and fed state can show significantly different wetting characteristics. Lecithin, pancreatic enzymes, glyceryl monooleate and sodium oleate have various solubilizing capacities. Surface active agents and phospholipid surrfactants in the dissolution media play an important role in the contact angle of the compound with water and thus influences dissolution rate of poorly soluble molecules. Lack of surface tension lowering agent in the dissolution media would give results that are not representative of in vivo rates (10).

The rate-limiting step in tablet disintegration is the penetration of dissolution media through the pores of the tablet. Liquid penetration into tablet pores is related to the pore structure and capillary tubes on the tablet surface. Washburn equation can be used to analyze liquid penetration:

$v^{2}=\frac{r \gamma \cos \theta t}{2 \eta}$

Where $v$ is the volume of liquid penetrated in time t, $\gamma$ the surface tension, $\theta$ contact angle, $\eta$ viscosity, and $\mathrm{r}$ is the capillary radius. Equation (1) indicates that the adhesion tension is the driving force for liquid penetration into solid dosage forms $(7,11)$.

\subsubsection{Cyclodextrin-Drug Complexation}

Some approaches to solubilize low water soluble drugs are complex formation with cyclodextrins or liposomes. Inclusion of poorly water soluble drug molecules into cyclodextrins improves its apparent solubility, physical and chemical stability and enhances its bioavailability. Evaluation of drugcyclodextrin association constant, $\mathrm{K}_{\mathrm{a}}$, can be accomplished by surface tension measurements at different concentrations of cyclodextrin. Interfacial tension measurement helps to understand the binding stochiometry of drug-cyclodextrin, and also to compare the inclusion complex of various kinds of cyclodextrins (12). Recently cyclodextrins have been associated with macromolecules to develop supramolecular assemblies. Daoud-Mahammed and co-workers have studied the formation of nanoassemblies of $\beta$-cyclodextrin polymer and a modified dextran. The formation mechanism and the structure of these nanoassemblies have been analyzed using surface tension measurements. A native $\beta$-cyclodextrin did not change the surface tension of modified dextran solution, however the addition of polymer $\beta$-cyclodextrin increased the surface tension indicating desorption of the modified dextran from the interface (13).

The inclusion complexes of antazoline and tetracaine with hydroxypropyl- $\beta$-cyclodextrin (HP$\beta$-CD) were measured at varying $\mathrm{pH}$ values of the solution. It was found that surface tension of the solution decreased with the increase in HP- $\beta-C D$ concentration as in Table 3 (14).

\subsubsection{Liposome Complexation}

During the past decades, one of the major challenges in pharmaceutical research was to improve the effectiveness of existing drug formulations using liposomal delivery systems. There are several advantages on these carriers, for example, hydrophobic, low water soluble drugs, such as steroids, can be incorporated into liposomes while hydrophilic drugs can be incorporated by partitioning and interacting with liquid bilayer of the liposomes. Liposomes are composed of phospholipids (PL) and cholesterol. An important step in liposome characterization is to determine the location of a drug within liposomes. Cholesterol occupies the same bilayer sites as lipophilic drugs such as steroids; so an increase in the amount of 


\begin{tabular}{lcl}
\hline \multicolumn{3}{l}{ Table 3. Surface tension of the solutions } \\
\hline Solution & $\mathrm{pH}$ & $\begin{array}{l}\text { Surface } \\
\text { tension } \\
(\mathrm{mN} / \mathrm{m})\end{array}$ \\
\hline HP- $\beta-C D ~ 33.1 \mathrm{mM}(\mathrm{NaCl})$ & 6.4 & 69.4 \\
& & \\
Antazoline HCl 33.1 mM (NaCl) & 6.2 & 58.5 \\
Antazoline HP- $\beta-C D ~ 1: 1$ & 9.6 & 49.4 \\
Antazoline HP- $\beta-C D ~ 1: 2$ & 9.7 & 55.9 \\
Antazoline HP- $\beta-C D ~ 1: 3$ & 9.7 & 59.9 \\
Tetracaine HCl 16.6 mM (NaCl) & 6.1 & 52.9 \\
Tetracaine HP- $\beta-C D ~ 1: 1$ & 8.4 & 44.4 \\
Tetracaine HP- $\beta-C D ~ 1: 2$ & 8.8 & 54.8 \\
Tetracaine HP- $\beta-C D ~ 1: 3$ & 8.6 & 61.3 \\
\hline
\end{tabular}

*Data taken from ref (14)

cholesterol reduces, prevents or changes the site of incorporation of those drug molecules. In other words there is competition between the lipophilic drug and cholesterol for space in the hydrophobic domain of the membrane, and as this space is limited, there might be no or less space for steroids when the cholesterol content is high. For the standardization and characterization of liposomal products, knowledge of various physical and chemical parameters is required including surface and the spreading behavior of phospholipids monolayer at gas/liquid interfaces. To find the optimal ratios of phospholipids/cholesterol/drug for maximal drug release and stability, surface tension of liposome should be estimated. The surface tension of liposomes is related to the phospholipid and cholesterol contents and is also affected by the drug concentration and decreases with increasing cholesterol concentration in the lipid bilayer. An increase in the drug concentration, without changing the lipid concentration, results in an increase of the surface tension of liposomes. The encapsulation efficiencies of drugs in liposomes were found to be influenced by molecular weight, surface tension and the aqueous solubility of the steroids (Table 4), whereby the most hydrophobic and least water-soluble steroid, triamcinolone hexacetonide, was found to be the most efficiently encapsulated drug amongst the four steroids tested $(15,16)$.

The main disadvantage of liposomes is their instability. Sedimentation is a technique used to study the stability of liposomal dispersions. It was
Table 4. Surface tension and aqueous solubility of steroids at $25^{\circ} \mathrm{C}^{*}$

\begin{tabular}{lll}
\hline Drug & $\begin{array}{l}\text { Surface tension } \\
(\mathrm{mN} / \mathrm{m})\end{array}$ & $\begin{array}{l}\text { Solubility } \\
(\mathrm{mg} / \mathrm{ml})\end{array}$ \\
\hline Hydrocortisone & $53.6 \pm 0.5$ & 0.260 \\
Triamcinolone & $49.4 \pm 0.9$ & 0.091 \\
$\begin{array}{c}\text { Triamcinolone } \\
\text { acetonide }\end{array}$ & $44.8 \pm 0.7$ & 0.018 \\
$\begin{array}{c}\text { Triamcinolone } \\
\text { hexacetonide }\end{array}$ & $42.2 \pm 0.4$ & 0.004 \\
\hline *Data adapted from ref (16). & \\
\hline
\end{tabular}

found that the sedimentation volume of liposomes changes with varying surface tensions of the liposomal formulations. Therefore, interfacial changes in liposomes can be used to determine their stability (17).

\subsection{Colloidal and Dispersed Systems}

\subsubsection{Emulsions}

Dispersed systems are regarded as a two-phase system in which the discontinuous phase, as droplet, is dispersed in a continuous phase. These dispersion systems have particles of size over $0.5^{\mu m}$. One of the most important properties of disperse systems is the vast interfacial area between dispersed and continuous phase. Therefore surface properties of dispersed systems are important. Emulsion systems are of great importance in systems such as parenteral drug delivery systems and personal care products (18). In these applications, a major challenge is the stability of the system. Changes in the stability will result in changes in droplet size. To produce small droplet size, the ratio of Laplace pressure difference and surface tension has to be controlled:

$\Delta P=\frac{2 \gamma}{r}$

Where $\Delta \mathrm{P}$ is the pressure difference across a curved interface, $\gamma$, the interfacial tension and $r$ the radius of the droplet (19).

When an emulsion system is destabilized, flocculation, coalescence and creaming normally occur before the final phase separation takes place. Coalescence is the final-irreversible stage of emulsion destabilization that involves the breaking of the interfacial film. The period of stability strongly depends on the characteristics of the interface separating the dispersed and continuous 
phase. Interfacial tension plays an important role when developing time and temperature stable emulsions (20). When the oil droplets are homogeneously dispersed, the surface tension of the emulsion increases. In contrast, when the oil droplets are concentrated at the surface of the system, surface tension of the emulsion decreases and creaming or coalescence occurs (21).

Surfactants and polymers act as foam and emulsion stabilizers. Surfactants work by lowering the surface tension of the disperse phase and miscuing it with the continuous phase $(21,22)$.

\subsubsection{Microemulsions}

Microemulsions (ME) possess properties of both emulsions (e.g. scattered laser light measurability of tiny particles) and those of solutions (no measurable interface tension between the oil and water components exists and they are thermodynamically stable). The primary factor controlling the size of $\mathrm{ME}$ is the physicochemical properties of the aqueous phase, oil phase and surfactants. The favorable drug delivery of $\mathrm{ME}$ is due to a very low surface tension (24). This characteristic of ME, having no or little surface tension, helps ME systems to spread easily on the skin and penetrate rapidly into the stratum corneum, when used as topical or transdermal formulations. Although ME systems have hydrophobic and lipophilic parts, but unlike emulsions they do not have continuous and discontinuous phases, which explains why ME systems penetrate into stratum corneum rapidly and easily (25). Release of drugs from microemulsions can be predicted by studying the physical characterization of ME such as density, electron conductivity and surface tension (26).

\subsection{Suspensions}

Suspension has a number of disadvantages as a dosage form. Problems such as uniformity, accuracy of dose, and sedimentation make suspension formulation much harder to achieve than of a tablet or capsule of the same drug. Repulsive and attractive forces between particles will cause a suspension to come together. Increasing or decreasing these forces respectively helps to obtain stable suspensions (27). These forces can be overcome by colloid milling or incorporating surface active agents, which reduce the thermodynamic driving force opposing dispersion of the particles. The lowering of the surface free energy can be expressed as follows:

$\Delta F=\gamma \Delta A$

Where $\mathrm{F}$ is the interfacial free energy, ${ }^{\gamma}$ the surface tension and $\triangle A$ is the increase in surface energy, by decreasing surface tension $\Delta F$ will be smaller leading to a more stable suspension (28). Dosage uniformity in suspensions is affected by flocculation, caking and poor re-dispersibility upon prolonged standing, which can be controlled by the addition of electrolytes, ionic detergents, non-ionic detergents or water-soluble polymers. Measuring surface tension would be a good approach to predict the flocculation and investigate redispersion time of suspensions and would help to achieve a suitable and stable formulation product $(29,30)$.

\subsection{Suppositories}

Many researchers have concentrated their efforts on rectal drug absorption of those drugs which currently must be injected to provide effective therapy, or those with difficult oral administration. They are useful dosage forms and are effective both locally and systemically. In most suppositories, the drug substance is in the form of suspension in the vehicle. In these cases, drug absorption is influenced by particle size, aqueous solubility and interfacial tension (31). In order to achieve a potent formulation the drug should have a low affinity to the suppository base and high affinity to the rectal fluid. Distribution coefficient of the drug in the suppository base-rectal liquid system will help to predict the drug release rate. HPLC technique can be used to predict the affinity of different drugs to any kind of suppository base. Capacity factor measured by chromatographic methods is an appropriate parameter for evaluating the affinity of compounds towards suppository base. Distribution behavior in suppository base is dependent on the surface tension of the drug, therefore drugs with high surface tension have lower affinity to the lipophilic suppository base and will partition into the rectal fluid easily (32).

\subsection{Eye Drops}

Several dosage forms are being used in ocular therapy. However, eye drops are the most common formulation. The average volume of a human tear is $7 \mu 1$. The conjunctival sac is capable of holding 20- 
$30 \mu \mathrm{l}$ fluids without overflowing onto the cheek; however the average drop size of a commercial topical medication is $39 \mu \mathrm{l}$. The excess fluid runs to the cheeks or drains to the naso-lacrimal system, where it will be absorbed systemically without firstpass metabolism by liver, and might cause unwanted side effects. To overcome this problem, several methods have been proposed $(33,34)$. The aim is to increase the efficacy by increasing ocular retention time while providing sufficient fluidity for ease of administration (35). One way to overcome this problem is to use non-ionic hydropolymers (36).

Reducing the size of the drop is another approach. This will decrease systemic drug loss, and improve the therapeutic bioavailability of the oculus. Dropper tips also control the size of the drops, therefore to get eye drops with ideal volume, dropper tips with small-dimension capillaries are necessary. The flow of the liquid through the capillary depends on the inner aperture and outer orifice diameter. These two factors influence viscosity and surface tension of the solution to be dispensed. However the formation of the drop at the orifice of capillary depends primarily on the surface tension of the solution. According to Tate's law:

$W=m g=2 \pi \gamma r$

Where $\mathrm{W}$ is the weight of the drop, $\mathrm{m}$ is the mass of the drop, $g$ is the acceleration of gravity, $\gamma$ is the surface tension of the liquid and $\mathrm{r}$ is the radius of the tip. This equation shows that a decrease in the surface tension (e.g. by adding surface active agents) will reduce the drop weight. The angle at which the dropper bottle is held is another factor which influences the drop size. When the dropper tip is being held at $45^{\circ}$ the cross sectional surface area is decreased compared to the upright position $90^{\circ}$, and this is due to the annular recess surrounding the outer orifice. The weight of a drop is proportional to the radius of the dropper tip; therefore, a decrease in the drop weight can be obtained when changing the angle from $90^{\circ}$ to $45^{\circ}$ as shown in Fig. 1 (34).

Another method to control droplet size of drugs formulated as emulsions is to prepare a microemulsion instead of an emulsion, which decreases the size of the droplet and helps to achieve a better therapeutic level (37).

Product sterilization is an important step when preparing parenteral and ocular medications. The rate at which heat is transferred into the content

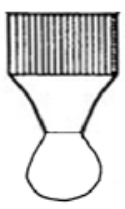

$90^{\circ}$

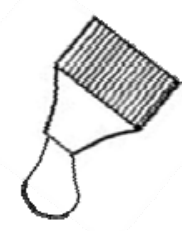

$45^{\circ}$
Figure 1. Effect of bottle tilting on the size of the droplet from ref (34).

of a container in an autoclave is dependent on the surface characteristics. Surface tension influences the rate at which heat is transferred from the steam to the container. When two phase systems for example emulsions or bacterial or biological cells in the formula are being sterilized, heat is transferred from one phase to another; therefore interfacial tension is considered an important factor (38).

Filtration of liquids is another important operation in pharmaceutical formulations. Filtration is defined as the separation of undissolved particles from liquid by passing the solutions through filters with certain pore radii. Membrane-based technologies such as ultrafiltration (UF), nanofiltration (NF) and reverse osmosis are employed in separation systems. Fouling tendency is a consequence of adsorption during the flow of solution components through the membrane material and results in nodule formation on the surface of the membranes influencing the performance of these membranes. Fouling effects cannot be completely avoided but can be reduced. Consequently, it is advantageous to reduce fouling by modifying the surface properties. Surface tension can be used to predict the adsorptive fouling tendency of membranes through the adhesion measurements (39-43). Surface tension is defined as the difference in surface energies between solvent molecules and polymer membrane surface. Solvent flux, J, through membrane pores can be expressed by the following equation:

$$
J=\frac{\Delta P}{\Phi\left[\left(\gamma_{c}-\gamma_{l}\right)+f_{1} \mu\right]+f_{2} \mu}
$$

Where ${ }^{\gamma_{c}}, \gamma_{l}$ are the critical surface tensions of the membrane and solvent, $f_{1}, f_{2}$ are membrane parameter characteristics of the membrane layers $\mathrm{NF}$ and UF, respectively, $\Phi$ is a solvent parameter and $\mu_{\text {is }}$ the viscosity of the solvent, and $\Delta P$ transmembrane pressure $(\mathrm{Pa})$. Optimizing the 
surface tension characteristics will increase solvent flux and reduce the fouling tendency (39).

\subsection{Topical and Transdermal Delivery Systems}

Contact angle measurements and calculations of surface free energy show that different parts of the skin on the body have different characteristics in terms of polarity which is due to the distribution of sebum glands on the skin (40). High contact angle value results in poor wettability of the skin surface (Fig. 2).

In general, surface tension of clean and dry human skin is $27-28$ dyne.cm $^{-1}$ (45). For any substrate to adhere to the surface of the skin, its surface energy must be equal to or less than that of the human skin. To design skin adhesives used in bandage, wound healing and transdermal systems, the considerations are; 1 . The product has to adhere to the skin for $24 \mathrm{~h}$ to 7 days; 2 . It should allow removal without excessive trauma to skin; 3 . Leave no residue on skin upon removal. In order to meet

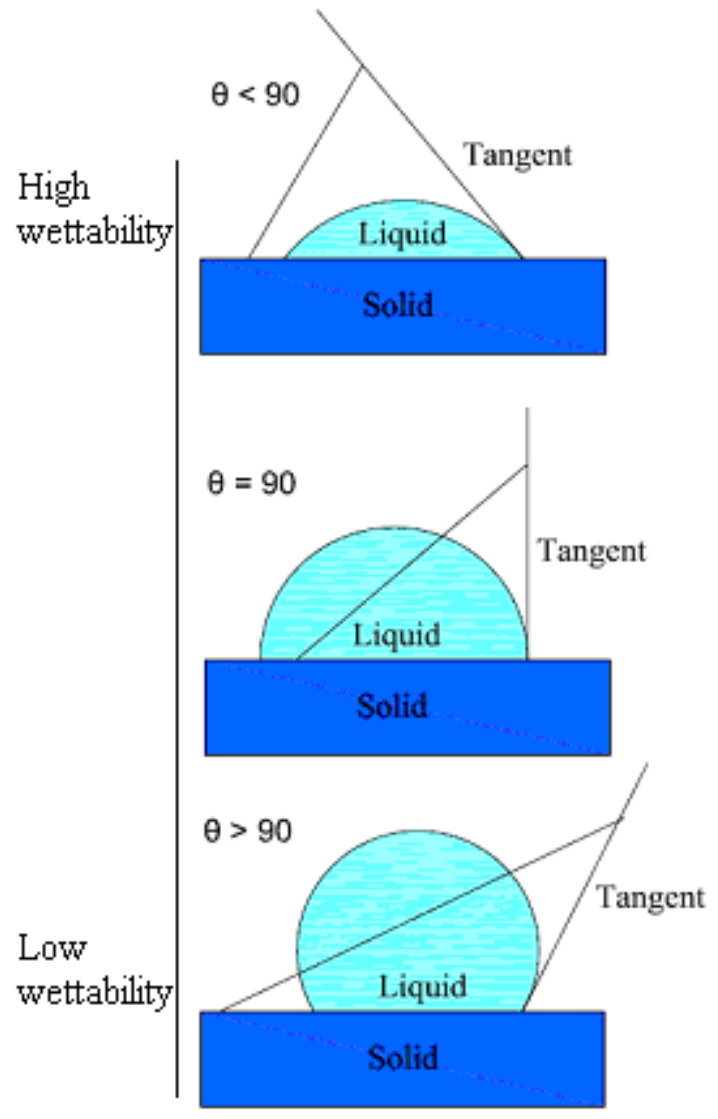

Figure 2. Schematic diagram of contact angle and wettability measurements. these challenges, contact angle measurements were performed (46). The main obstacle for transdermal drug delivery is the stratum corneum that forms a permeation barrier of drugs. Several techniques have been used to increase drug penetration across the skin including the use of penetration enhancers that disrupts the stratum corneum. Chemical penetration enhancers, such as surfactants, interact with keratin, swell stratum corneum and extract the intercellular lipid matrix of the stratum corneum. Reducing drug/skin interfacial tension improves the contact between the drug and skin and leads to enhanced permeation of the drug through stratum corneum. Some drugs, such as ibuprofen, have shown ionic surfactant activity; therefore acting as self-penetration enhancers (47).

Textural, rheological and physical properties of topical drug delivery systems have a direct influence on the drug availability. These characteristics are important for the appearance, feel, and application of a topical drug formulation. Therefore, the composition of a drug vehicle should be considered in its nomenclature. Some products have low surface tensions and spread rapidly and easily on the surface of skin, while others are difficult to apply to the surface. Study of the physical properties such as surface tension of topical products can be used to provide a more scientific basis for the classification of topical dosage forms, and as a guide for physicians when prescribing topical drugs (48).

\subsection{Nasal Aerosols}

The delivery of drugs to the lung is an excellent alternative to oral delivery systems, because the dose and the incidence of systemic side effect can be reduced. Pharmaceutical aerosols may be formulated as solutions, suspensions, emulsions and powders. Physicochemical characteristics of the active ingredient, particle size and shape of the drug and concentration of surface-active agent used are important formulation factors (49). Aerosols could be generated using nebulization of aqueous drug solutions, suspension or dispersion or by using a dry powder formulation administered by a metered dose inhaler (50). Irrespective of the technique, the aerosol size distribution and particle adhesion are important variables that influence aerosolisation efficiency (51). The droplets should be sufficiently small to reach the alveolar region. An aerosol for the delivery of drugs to the lungs must be of 
optimal particle size. Particle size in the range of 1$5 \mu \mathrm{m}$ is considered appropriate for the delivery of therapeutic agents to the alveolar region. These micronised particles have high surface areas, and surface free energies. As the system attempts to minimize the surface free energy, aggregation of the drug and/or adhesion to the container wall occurs. Formulation improvements could be made by estimating the adhesion and aggregation properties of the drug to the container (52-55). It was found that surface roughness is not a significant factor of adhesion interaction between active pharmaceutical ingredients and pressurized metered dose inhaler (pMDI), however the polar components of surface energy has greater influence on adhesive events. Therefore, by considering the surface polar energies, adhesion force can be minimized and more efficient pMDI systems can be developed (56).

Factors such as surface tension and viscosity control the output of aerosol particles from nebulizers and atomizer. A decrease in the surface tension of the nebulizing solution allows the production of small droplets by the nebulizer, which increases the output and allows a logical and reliable approach to the formulation of inhalers (52$54)$.

\section{Drug Analysis}

Pharmaceutical formulations are complex mixtures of active and inert materials. To ensure quality and stability of the final products, the pharmaceutical analyst must be able to analyze these mixtures.

\subsection{Chromatography}

Chromatographic techniques are among the most powerful techniques available. They achieve their ability to separate mixtures by retarding the passage of some components while permitting others to move freely, this property can be calculated using retention factor $(\mathrm{k})(57,58)$. Retention factor is a parameter that expresses the ability of a particular solute to interact with a chromatographic system, it relates to the contact surface area of the substance ( $\delta A$ ) according to the following equation:

$\ln k=B+\frac{N}{R T} \delta A \cdot \gamma$

Where B is constant for strictly homologous series, $\mathrm{N}$, Avogadro number and $\gamma_{\text {is surface tension of }}$ solution, $R$ is the gas constant and $T$ the temperature (57). Retention factor depends on physicochemical properties of the solute, stationary phase and mobile phase such as $\log \mathrm{P}, \log \mathrm{D}$, surface tension, $\mathrm{pH}$ and $\mathrm{pK}_{\mathrm{a}}$. These factors show the interaction of solute with stationary and mobile phases. Artificial neural networks (ANNs) can be used to correlate retention time (and also retention factor) to molecular structure and therefore help to better understand and predict the retention factor of molecules (59).

\subsection{Mass Spectroscopy}

Mass spectrometry has proven to be one of the most effective techniques in biomedical research, particularly for the analysis of complex mixtures in biological samples. Its high sensitivity, specificity, and easy combination with chromatographic techniques make it the method of choice of many analysts. Influence of solvent properties on the efficacy, speed of analysis, and detection sensitivity and performance in separation systems such as capillary electrophoresis-mass spectrometry and electrospray ionization mass spectrometry cannot be neglected $(60,61)$. For example, the physical properties of the solution such as surface tension, conductivity and viscosity affect the mechanism by which ions are produced during electrospray ionization. The electrospray current can be expressed as:

$I=\beta(\varepsilon)\left(\frac{Q K \gamma}{\varepsilon}\right)^{\frac{1}{2}}$

Where I is the total spray current or total excess charges in the electrospray, $\mathrm{K}$ is the electric conductivity of the liquid, $\gamma$ surface tension of the liquid, $\varepsilon$, the dielectric constant of the liquid, $\beta(\varepsilon)$ is the experimentally determined coefficient, $\mathrm{Q}$, liquid flow rate $(60,62)$.

\section{CONCLUSION}

Surface chemistry has a large influence in many industries. The application of the knowledge of surface tension is of utmost importance to yield new and better performing products. Surface tension can influence the development, production and performance of pharmaceutical, food, biomaterial and other products. Considerations of parameters such as contact angle and surface tension of surfaces may provide the critical component to solve industrial problems and improve product 
quality.

\section{REFERENCES}

1. Rowe RC. Correlation between predicted binder spreading coefficients and measured granule and tablet properties in the granulation of paracetamol. Int J Pharm, 1990; 58: 209-213.

2. Parker MD, York P, Rowe RC. Binder-substrate interactions in wet granulation. 2: The effect of binder molecular weight. Int J Pharm, 1991; 12: 243-249.

3. Riley CK, Adebayo SA, Wheatley A, Asemota HN. Surface properties of yam (Dioscorea sp.) starch powders and potential for use as binders and disintegrants in drug formulations. Powder Technol, 2008; 185: 280-285.

4. Luner PE, Babu SR, Mehta SC. Wettability of a hydrophobic drug by surfactant solutions. Int $\mathrm{J}$ Pharm, 1996; 128: 29-44.

5. Wulf M, Uhlmann P, Michel S, Grundke K. Surface tension studies of leveling additives in powder coatings. Prog Org Coat, 2000; 38: 59-66.

6. Machiste EO, Buckon G. Dynamic surface tension studies of hydroxypropylmethyl-cellulose filmcoating solutions. Int J Pharm, 1996; 145: 197-201.

7. Fell JT, Mohammad HAH. The wetting of powders by bile salt solutions and gastric juice. Int J Pharm, 1995; 125: 327-330.

8. Hörter D, Dressman JB. Influence of physicochemical properties on dissolution of drugs in the gastrointestinal tract. Adv Drug Deliv Rev, 2001; 46: 75-87.

9. Sunada H, Bi Y. Preparation, evaluation and optimization of rapidly disintegrating tablets. Powder Technol, 2002; 122: 188-198.

10. McConnell EL, Fadda HM, Basit AW. Gut instincts: Explorations in intestinal physiology and drug delivery. Int J Pharm, 2008; 364: 213-226.

11. Anwar S, Fell JT, Dickinson PA. An investigation of the disintegration of tablets in biorelevant media. Int J Pharm, 2005; 290: 121-127.

12. Angelova A, Ringard-Lefebvre C, Baszkin A. Drugcyclodextrin association constants determined by surface tension and surface pressure measurements I. Host-guest complexation of water soluble drug by cyclodextrins: polymyxin B- $\beta$ cyclodextrin system. J Colloid Interface Sci, 1999; 212: 275-279.

13. Daoud-Mahammed S, Ringard-Lefebvre C, Razzouq N, Rosilio V, Gillet B, Couvreur P, Amiel C, Gref R. Spontaneous association of hydrophobized dextran and poly- $\beta$-cyclodextrin into nanoassemblies. Formation and interaction with a hydrophobic drug. J Colloid Interface, 2007; 307: 83-93.

14. Van Santvliet L, Ludwig A. The influence of penetration enhancers on the volume instilled of eye drops. Eur J Pharm Biopharm, 1998; 45: 189-198.

15. Vargha-Butler EI, Hurst EL. Study of liposomal drug delivery systems 1 . Surface characterization of steroid loaded MLV liposomes. Colloids Surf B, 1995; 3: 287-295.

16. Kulkarni SB, Vargha-Butler EI. Study of liposomal drug delivery systems 2. Encapsulation efficiencies of some steroids in MLV liposomes. Colloids Surf B, 1995; 4: 77-85.

17. Vargha-Butler EI, Foldvari M, Mezei M. Study of the sedimentation behavior of liposomal drug delivery system. Colloids Surf, 1989; 42: 375-389.

18. Blomberg E, Clesson PM, Warnheim T. Surface interactions in emulsions and liposome solutions. Colloids Surf A, 1999; 159: 149-157.

19. Friberg SE, Quencer LG, Hiton ML. Theory of emulsion. In: Lieberman, HA, Rieger MM, Banker GS. Pharmaceutical Dosage Forms: Disperse Systems, Marcel Dekker, NY, USA, pp 54-55. 1996.

20. Shi L, Miller C, Caldwell KD, Valint P. Effects of mucin addition on the stability of oil-water emulsions. Colloid Surf B, 1999; 15: 303-312.

21. Kawaguchi E, Shimokawa K-i, Ishii F. Physicochemical properties of structured phosphatidylcholine in drug carrier lipid emulsions for drug delivery systems. Colloid Surf B, 2008; 62: 130-135.

22. Wilde M. Interfaces: Their role in foam and emulsion behaviour. Curr Opin Colloid Interface Sci, 2000; 5: 176-181.

23. Tcholakova S, Denkov ND, Ivanov IB, Campbell B. Coalescence stability of emulsions containing globular milk proteins. Adv Colloid Interface Sci, 2006; 123-126: 259-293.

24. Kreilgaard M. Influence of microemulsions on cutaneous drug delivery. Adv Drug Deliv Rev, 2002; 54: S77-S98.

25. Lehmann L, Keipert S, Gloor M. Effects of microemulsions on the stratum corneum and hydrocortisone penetration. Eur J Pharm Biopharm, 2001; 52: 129-36.

26. Podlogar F, Bešter Rogač M, Gašperlin M. The effect of internal structure of selected water-Tween 40-Imwitor 308-IPM microemulsions on ketoprofene release. Int J Pharm, 2005; 302: 68-77.

27. Gabrielli G, Cantale F, Guarini GGT. Adsorption of amphiphilic mixtures and stabilization of suspensions of hydrophobic solids in water. Colloids Surf A, 1996; 119: 163-174.

28. Swarbrick J, Rubino JT, Rubino OP. Coarse dispersions In: Gennaro AR. Remington: The Science of Practice of Pharmacy, $20^{\text {th }}$ Ed, Lippincott William and Wilkins, USA, pp. 316-319, 2000.

29. Loimer T, Nir A, Semiat R. Shear-induced corrugation of free interfaces in concentrated suspensions. J Non-Newtonian Fluid Mech, 2002; 102: 115-134. 
30. Yasueda S-I, Inada K, Matsushisa K, Terayama H, Ohtori A. Evaluation of ophthalmic suspensions using surface tension. Eur J Pharm Biopharm, 2004; 57: 377-382.

31. Hermann TW. Recent research on bioavailability of drugs from suppositories. Int J Pharm, 1995; 123:111.

32. Dimitrova B, Doytchinova I, latkova M. Reversedphase high-performance liquid chromatography for evaluating the distribution of pharmaceutical substances in suppository base-phosphate buffer system. J Pharm Biomed Anal, 2000; 23: 955-964.

33. Ceulemans J, Vermeire A, Adriaens E, Remon JP, Ludwig A. Evaluation of mucoadhesive tablet for ocular use. J Control Release, 2001; 77: 333-344.

34. Van Santvliet L, Ludwig A. Influence of the physico-chemical properties of ophthalmic viscolayers on the weight of drops dispensed from a flexible dropper bottle. Eur J Pharm Biopharm, 1999; 7: 339-345.

35. Chan J, El Maghraby GMM, Craig JP, Alany RG. Phase transition water-in-oil microemulsions as ocular drug delivery systems: In vitro and in vivo evaluation. Int J Pharm, 2007; 328: 65-71.

36. Vandamme ThF, Brobeck L. Poly (amidoamine) dendrimers as ophthalmic vehicles for ocular delivery of pilocarpine nitrate and tropicamide. $\mathrm{J}$ Control Release, 2005; 102: 23-38.

37. Schulz MB, Daniels R. Hydroxypropylmethylcellulose (HPMC) as emulsifier for submicron emulsions: Influence of molecular weight and substitution type on the droplet size after highpressure homogenization. Eur J Pharm Biopharm, 2000; 49: 231-236.

38. Kartinos NJ, Groves MJ. Manufacturing of large volume parentral. In: Avis KE, Lachman L, Lieberman HA. Pharmaceutical Dosage Forms: Parenteral Medication, Marcel Dekker, NY, USA, pp 266-271, 1984.

39. Machado DR, Hasson D, Semiat R. Effect of solvent properties on permeate flow through nanofiltration membranes. Part II Transport model. J Membr Sci, 2000; 166: 63-69.

40. Sarmento LAV, Spricigo CB, Petrus JCC, Carlson LHC, Machado RAF. Performance of reverse osmosis membranes in the separation of supercritical $\mathrm{CO}_{2}$ and essential oils. J Membr Sci, 2004; 237: 7176.

41. Tan JMA, Noh SH, Chowdhurry G, Matsuura T. Influence of surface tensions of solvent/nonsolvent mixtures in membrane casting solutions on the performance of poly (2, 6-dimethyl-1, 4-phenylene) oxide membranes for gas separation applications. $\mathrm{J}$ Membr Sci, 2000; 174: 225-230.

42. Xu Z, Li L, Wu F, Tan S, Zhang Z. The application of the modified PVDF ultrafiltration membranes in further purification of Ginkgo Biloba extraction. J
Membr Sci, 2005; 255: 125-131.

43. Wang J, Yue Z, Ince JS, Economy J. Preparation of nanofiltration membranes from polyacrylonitrile ultrafiltration membranes. J Membr Sci, 2006; 286: 333-341.

44. Mavon A, Zahouani H, Redoules D, Agache P, Gall Y, Humbert P. Sebum and stratum corneum lipids increase human skin surface free energy as determined from contact angle measurements: A study on two anatomical sites. Colloids Surf B, 1997; 8: 147-155.

45. Ginn ME, Noyees CM, Jungermann E. The contact angle of water on viable human skin. J Colloid Interface Sci, 1968; 26: 146-151.

46. Venkatraman S, Gale R. Skin adhesives and skin adhesion: 1. Transdermal drug delivery systems. Biomaterials, 1998; 19: 1119-1136.

47. Al-Saidan SM. Transdermal self-permeation enhancement of ibuprofen. J Control Release, 2004; 100: 199-209.

48. Buhse L, Kolinski R, Westenberger B, Wokovich A, Spencer J, Chen CW, Turujman S, Gautam-Basak M, Kang GJ, Kibbe A, Heintzelman B, Wolfgang E. Topical drug classification. Int J Pharm, 2005; 295: 101-112.

49. Butler Ellis MC, Tuck CR, Miller PCH. How surface tension of surfactant solutions influences the characteristics of sprays produced by hydraulic nozzles used for pesticide application. Colloids Surf A, 2001; 180: 267-276.

50. Steckel H, Müller BW. Metered-dose inhaler formulation with beclomethasone-17, 21dipropionate using the ozone friendly propellant $\mathrm{R}$ 134a. Eur J Pharm Biopharm, 1998; 46: 77-83.

51. Salama R, Hoe S, Chan H-K, Traini D, Young PM. Preparation and characterization of controlled release co-spray dried drug-polymer microparticles for inhalation 1: Influence of polymer concentration on physical and in vitro characteristics. Eur J Pharm Biopharm, 2008; 69: 486-495.

52. Parsons GE, Buckton G, Chatham SM. The use of surface energy and polarity determinations to predict physical stability of non-polar, non-aqueous suspensions. Int J Pharm, 1992; 83: 163-170.

53. Steckel H, Eskanadar F, Withhohn K. Effect of cryoprotectants on the stability and aerosol performance of nebulized aviscumine, a $57-\mathrm{kDa}$ protein. Eur J Pharm Biopharm, 2003; 56: 11-21.

54. Davis SS. Physico-chemical studies on aerosol solutions for drug delivery 1 . Water-propylene glycol systems. Int J Pharm, 1978; 1: 71-83.

55. German WG, Hall GD. Inhalation Aerosols. In: Swarbrick J. Current Concepts in the Pharmaceutical Sciences. Dosage Form Design and Bioavailability, Lea and Febiger, Philadelphia, pp. 97-99, 1973.

56. James J, Davies M, Toon R, Jinks P, Roberts CJ. Particulate drug interactions with polymeric and 
elastomeric valve components in suspension formulations for metered dose inhalers. Int J Pharm, 2009; 366: 124-132.

57. Osella D, Gambino O, Nervi C, Ravera M. HPLC studies of $\mathrm{Fe}_{2}(\mathrm{CO})_{6}$ (ligand) complexes. J Organomet Chem, 1992; 433: 287-294.

58. Walter TH, Iraneta $\mathrm{P}$, Capparella M. Mechanism of retension loss when $\mathrm{C}_{8}$ and $\mathrm{C}_{18}$ HPLC columns are used with highly aqueous mobile phases. J Chromatogr A, 2005; 1075: 177-183.

59. Agatonovic-Kustrin S, Zecevic M, Zivanovic L. Use of ANN modelling in structure-retention relationships of diuretics in RP-HPLC. J Pharm Biomed Anal, 1999; 21: 95-103.
60. Mathis JA, McCord BR. Mobile phase influence on electorspray ionization for the analysis of smokeless powders by gradient reversed phase highperformance liquid chromatography-ESIMS. Forensic Sci Int, 2005; 154: 159-166.

61. Steiner F, Hassel M. Influence of solvent properties on separation and detection performance in nonaqueous capillary electrophoresis-mass spectrometry of basic analytes. J Chromatogr A, 2005; 1068: 131142.

62. Tang K, Page JS, Smith DR. Charge competition and the linear dynamic range of detection in electrospray inonization mass spectrometry. J Am Soc Mass Spectrom, 2004; 15: 1416-1423. 